\title{
About Photocatalytic Properties of Some Heterostructures Based on Strontium Bismuthate
}

\section{Dmitry Sergeevich Shtarev ${ }^{1, a^{*}}$, Anna Vladimirovna Shtareva ${ }^{1,2, b}$,} Maxim Sergeevich Molokeev ${ }^{2,3,4, c}$, Alexander Vjacheslavovich Syuy ${ }^{2, d}$ and Egor Olegovich Nashchochin ${ }^{2, \mathrm{e}}$

${ }^{1}$ Institute of Tectonics and Geophysics Named After Yu.A. Kosygin of Far Eastern Branch of the Russian Academy of Sciences, Khabarovsk, Russia

${ }^{2}$ Far Eastern State Transport University, 47 Seryshev St., Khabarovsk 680021, Russia

${ }^{3}$ Kirensky Institute of Physics, Akademgorodok 50, bld. 38, Krasnoyarsk, 660036 Russia

${ }^{4}$ Siberian Federal University, 79 Svobodny pr., 660041 Krasnoyarsk, Russia

ashtarev@mail.ru, bshtareva_anna@mail.ru, cmsmolokeev@mail.ru, dalsyuy271@gmail.com, enashchochin@gmail.com

Keywords: strontium bismuthate, alkaline earth metal bismuthate, heterostructure, diffuse reflectance spectroscopy, visible light active photocatalysts, photocatalytic activity.

Abstract. In the work, some heterostructures consisting of two different strontium bismuthates from the following series are investigated: $\mathrm{Sr}_{2} \mathrm{Bi}_{2} \mathrm{O}_{5}, \mathrm{Sr}_{3} \mathrm{Bi}_{2} \mathrm{O}_{6}$ and $\mathrm{Sr}_{6} \mathrm{Bi}_{2} \mathrm{O}_{11}$. It is shown that the creation of such heterostructures affects both optical and photocatalytic properties. The results obtained are promising for the further development and research of new heterostructures based on two different strontium bismuthates and for studying the characteristics of their photocatalytic activity.

\section{Introduction}

Strontium bismuthates are promising photocatalysts of visible light for various applications [17]. To date, photocatalytic properties of a significant amount of strontium bismuthate (Fig. 1, left), as well as a number of strontium bismuthate-based heterostructures, have been investigated [9].
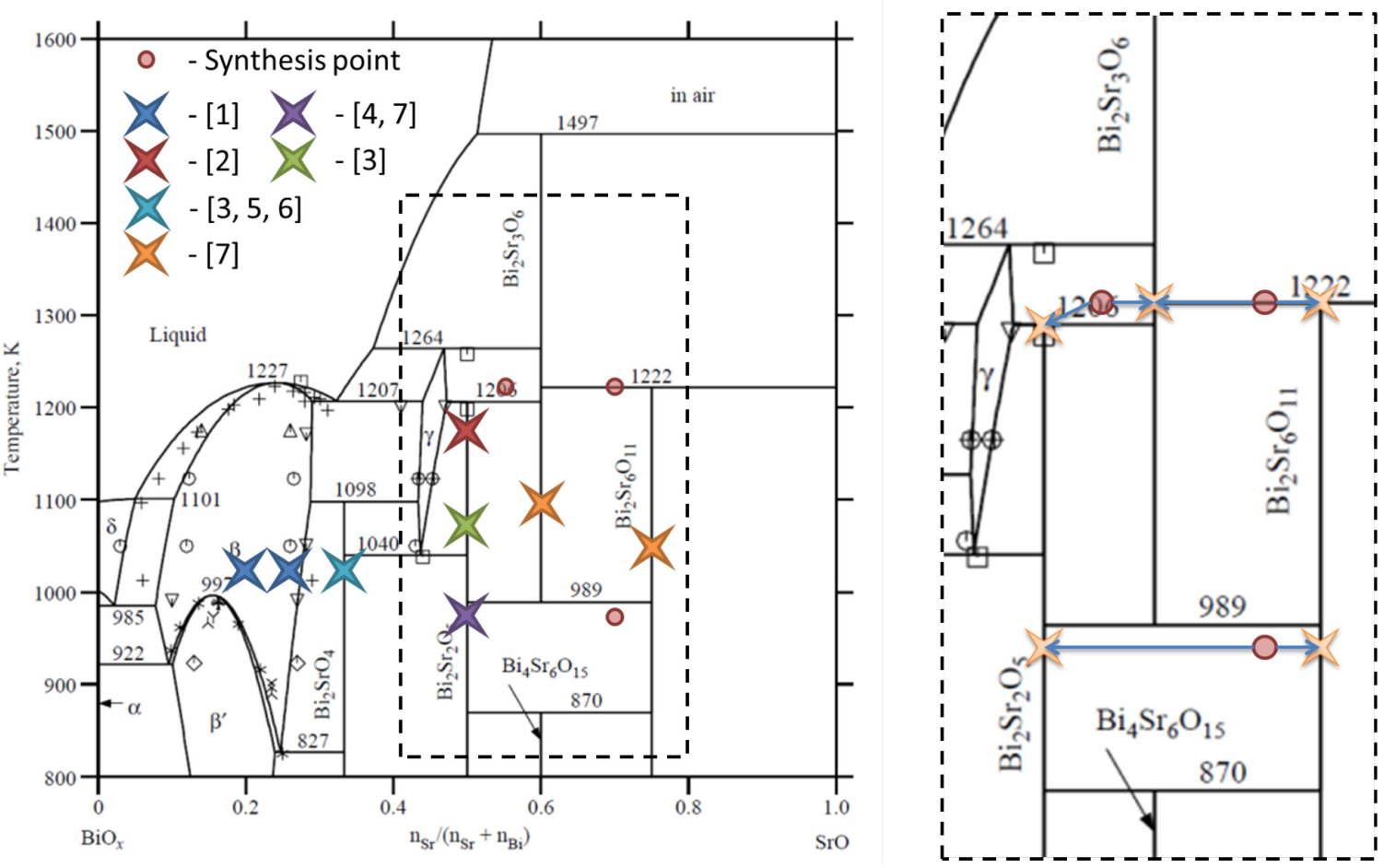

Fig. 1. Phase diagram of strontium bismuthate [8] (left) and the formation of various heterostructures (right). 
In this paper, we study the photocatalytic properties of heterostructures consisting of two different strontium bismuthates from the following series: $\mathrm{Sr}_{2} \mathrm{Bi}_{2} \mathrm{O}_{5}, \mathrm{Sr}_{3} \mathrm{Bi}_{2} \mathrm{O}_{6}$, and $\mathrm{Sr}_{6} \mathrm{Bi}_{2} \mathrm{O}_{11}$.

\section{Synthesis of the Strontium Bismuthates Heterostructures}

For the synthesis of strontium bismuth heterostructures the solid-state synthesis was used. Bismuth oxide and strontium nitrate were used as a precursors. Solid-state synthesis was conducted in 2 stages: at the first stage precursors were aged at $918 \mathrm{~K}$ for 2 hours, at the second stage -72 hours at different temperatures.

To obtain the $\mathrm{Sr}_{2} \mathrm{Bi}_{2} \mathrm{O}_{5} / \mathrm{Sr}_{3} \mathrm{Bi}_{2} \mathrm{O}_{6}$ heterostructure, a point on the phase diagram was selected, corresponding to $55 \mathrm{~mol} \%$ of strontium and $1223 \mathrm{~K}$. As can be seen from the scheme of formation of heterostructures (Fig. 1, right), under such conditions, the formation of two phases of strontium bismuthate $-\mathrm{Sr}_{2} \mathrm{Bi}_{2} \mathrm{O}_{5}$ and $\mathrm{Sr}_{3} \mathrm{Bi}_{2} \mathrm{O}_{6}$ - which forms the heterostructure.

The preparation of the $\mathrm{Sr}_{3} \mathrm{Bi}_{2} \mathrm{O}_{6} / \mathrm{Sr}_{6} \mathrm{Bi}_{2} \mathrm{O}_{11}$ heterostructure was carried out on the same principle and did not cause any particular difficulties. For this, a point in the phase diagram was selected, corresponding to $70 \mathrm{~mol} . \%$ of strontium and $1223 \mathrm{~K}$. As can be seen from the scheme of formation of heterostructures (Fig. 1, right), under these conditions, the formation of two "neighboring" phases of strontium bismuthate, $\mathrm{Sr}_{3} \mathrm{Bi}_{2} \mathrm{O}_{6}$ and $\mathrm{Sr}_{6} \mathrm{Bi}_{2} \mathrm{O}_{11}$, which forms the heterostructure.

Obtaining the $\mathrm{Sr}_{2} \mathrm{Bi}_{2} \mathrm{O}_{5} / \mathrm{Sr}_{6} \mathrm{Bi}_{2} \mathrm{O}_{11}$ heterostructure poses a certain difficulty - between these two phases of strontium bismuthate, the $\mathrm{Sr}_{6} \mathrm{Bi}_{4} \mathrm{O}_{15}$ and $\mathrm{Sr}_{3} \mathrm{Bi}_{2} \mathrm{O}_{6}$ phases are present in the phase diagram. However, the phase diagram contains a "window" in the range of 870-989 K, in which these two phases are not formed. Therefore, to obtain the $\mathrm{Sr}_{2} \mathrm{Bi}_{2} \mathrm{O}_{5} / \mathrm{Sr}_{6} \mathrm{Bi}_{2} \mathrm{O}_{11}$ heterostructure, a point was chosen on the phase diagram corresponding to $70 \mathrm{~mol} \%$ of strontium and $973 \mathrm{~K}$. As can be seen from the scheme of formation of heterostructures (Fig. 1, right), under such conditions, the formation of two phases of strontium bismuthate, $\mathrm{Sr}_{2} \mathrm{Bi}_{2} \mathrm{O}_{5}$ and $\mathrm{Sr}_{6} \mathrm{Bi}_{2} \mathrm{O}_{11}$, which forms the heterostructure.

\section{XRD Characterization}

After receiving all the samples of heterostructures were investigated by XRD method to confirm their composition and the absence of impurities of other phases of strontium bismuthate. XRD analyzes were performed using a Mini Flex II diffractometer (Japan) with CuK $\alpha$ radiation $(\lambda=$ $1.5406 \AA)$ in the range $10 \leq 2 \theta \leq 80$ degrees at a time of $2 \mathrm{deg} . / \mathrm{min}$. Phase identification was performed using the PDF-2 database. XRD spectra are shown in Fig. 2.

The determination of the mass fraction of the phases was carried out using the «Search Match!» software package. Mass fractions of individual strontium bismuthates in the composition of the synthesized heterostructures are presented in Table 1.

Table 1. Part of the component in the heterostructure.

\begin{tabular}{|c|c|c|c|}
\hline Sample & $\mathrm{Sr}_{2} \mathrm{Bi}_{2} \mathrm{O}_{5}$ & $\mathrm{Sr}_{3} \mathrm{Bi}_{2} \mathrm{O}_{6}$ & $\mathrm{Sr}_{6} \mathrm{Bi}_{2} \mathrm{O}_{11}$ \\
\hline $\mathrm{Sr}_{2} \mathrm{Bi}_{2} \mathrm{O}_{5} / \mathrm{Sr}_{3} \mathrm{Bi}_{2} \mathrm{O}_{6}$ & $5 \%$ & $95 \%$ & - \\
\hline $\mathrm{Sr}_{2} \mathrm{Bi}_{2} \mathrm{O}_{5} / \mathrm{Sr}_{6} \mathrm{Bi}_{2} \mathrm{O}_{11}$ & $11 \%$ & - & $89 \%$ \\
\hline $\mathrm{Sr}_{3} \mathrm{Bi}_{2} \mathrm{O}_{6} / \mathrm{Sr}_{6} \mathrm{Bi}_{2} \mathrm{O}_{11}$ & - & $10 \%$ & $90 \%$ \\
\hline
\end{tabular}

Earlier [7], it was shown that strontium bismuth $\mathrm{Sr}_{2} \mathrm{Bi}_{2} \mathrm{O}_{5}$ does not possess significant photocatalytic activity. Therefore, in the $\mathrm{Sr}_{2} \mathrm{Bi}_{2} \mathrm{O}_{5} / \mathrm{Sr}_{3} \mathrm{Bi}_{2} \mathrm{O}_{6}$ heterostructure, the fraction of this strontium bismuthate in the heterostructure is only $5 \%$, the basis of this heterostructure (95\%) is 
strontium bismuthate $\mathrm{Sr}_{3} \mathrm{Bi}_{2} \mathrm{O}_{6}$. The same considerations are due to the composition of the other two heterostructures. Strontium bismuthate $\mathrm{Sr}_{2} \mathrm{Bi}_{2} \mathrm{O}_{5}$ has a significantly lower photocatalytic activity compared to strontium bismuthate $\mathrm{Sr}_{6} \mathrm{Bi}_{2} \mathrm{O}_{11}$. Therefore, in the $\mathrm{Sr}_{3} \mathrm{Bi}_{2} \mathrm{O}_{6} / \mathrm{Sr}_{6} \mathrm{Bi}_{2} \mathrm{O}_{11}$ and $\mathrm{Sr}_{2} \mathrm{Bi}_{2} \mathrm{O}_{5} / \mathrm{Sr}_{6} \mathrm{Bi}_{2} \mathrm{O}_{11}$ heterostructures, the more active phases of strontium bismuthate form the basis (about 90\%).

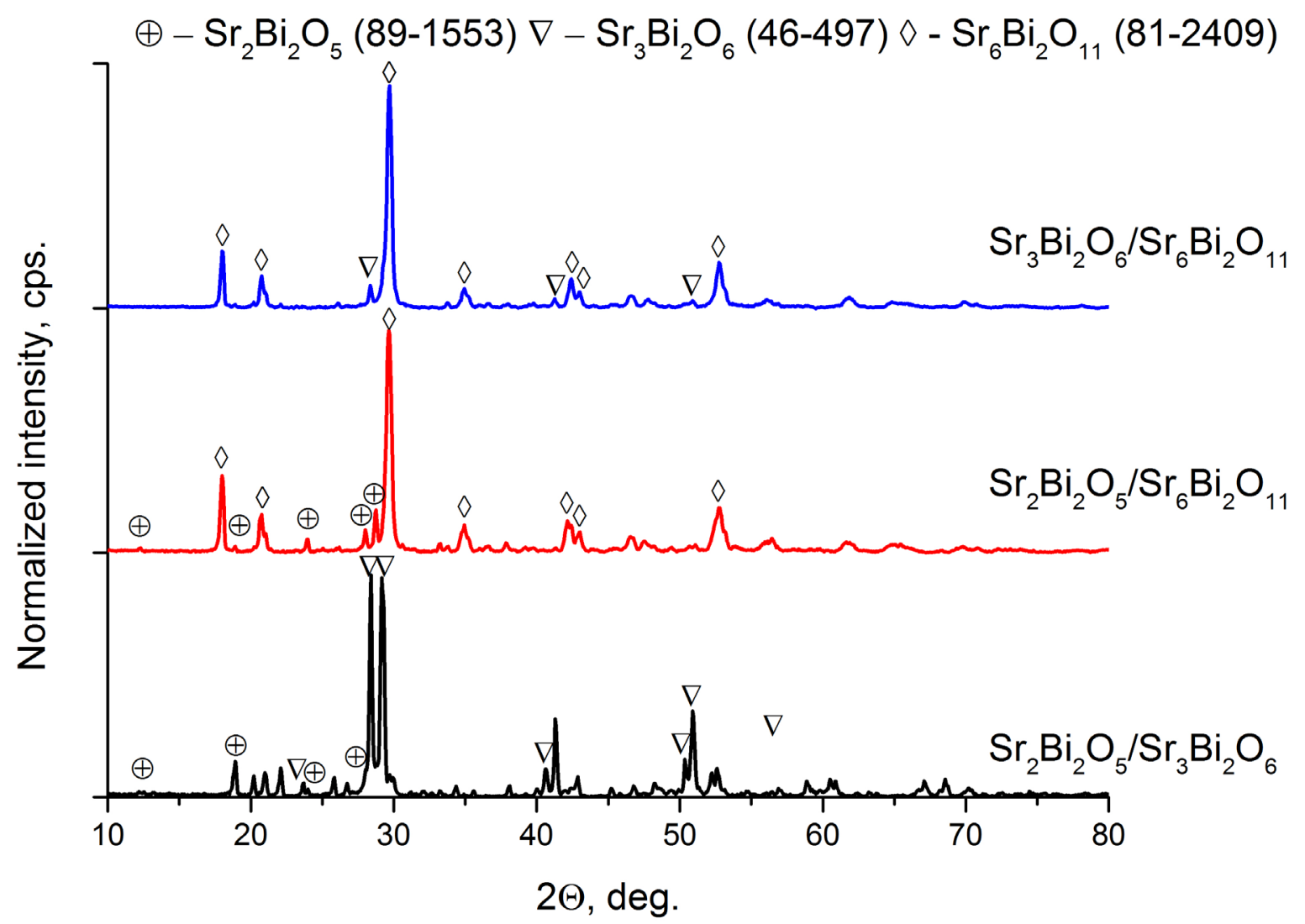

Fig. 2. X-ray phase analysis of obtained samples. Markers mark characteristic peaks of various strontium bismuthate in heterostructures.

\section{Diffuse Reflectance Spectroscopy}

The optical properties of the synthesized heterostructures from different strontium bismuthates were studied by diffuse reflectance spectroscopy. The focus of these studies was on the influence of the composition of the heterostructures on the position and shape of the intrinsic absorption edge. Diffuse reflectance spectra, as $A(\lambda)$, were recorded in the 250-1200 nm spectral range under ambient conditions on a Cary $5000 \mathrm{UV} /$ vis/NIR spectrophotometer equipped with a DRA 2500 external diffuse reflectance accessory; optical-grade $\mathrm{BaSO}_{4}$ was the reference standard. In Fig. 3 shows the DRS spectra of all synthesized heterostructures based on strontium bismuthate. 


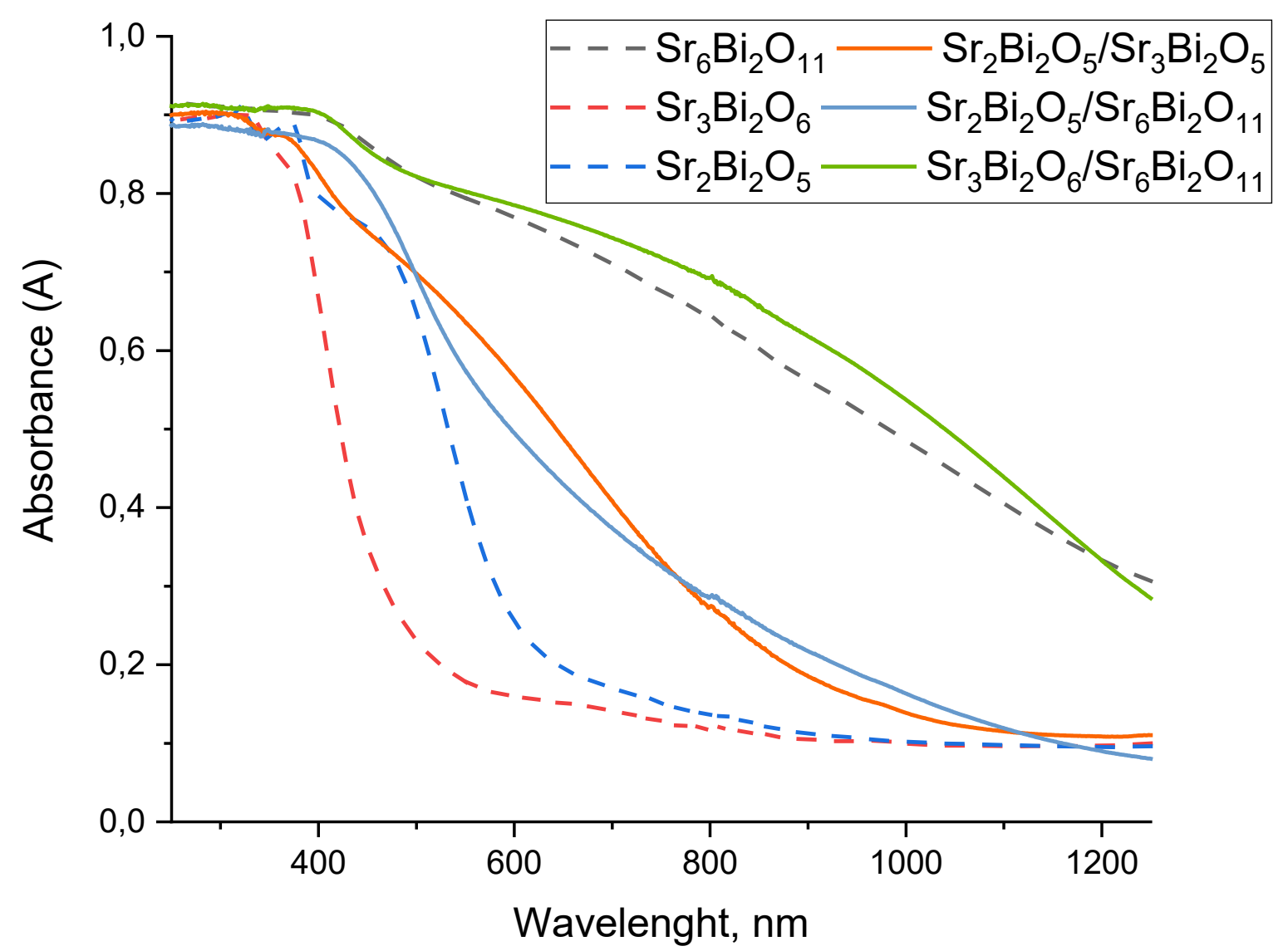

Fig. 3. DRS spectra of synthesized heterostructures. For comparison, the DRS spectra of the pure phases of strontium bismuthate (taken from [7]).

It is seen that the formation of heterostructures in all cases leads to a significant change in absorption in the extrinsic area. In the $\mathrm{Sr}_{2} \mathrm{Bi}_{2} \mathrm{O}_{5} / \mathrm{Sr}_{3} \mathrm{Bi}_{2} \mathrm{O}_{6}$ heterostructure, the introduction of a small (5\%) amount of strontium bismuthate $\mathrm{Sr}_{2} \mathrm{Bi}_{2} \mathrm{O}_{5}$ is accompanied by the appearance of a significant absorption in the region 400-850 $\mathrm{nm}$. The following picture is observed for the $\mathrm{Sr}_{2} \mathrm{Bi}_{2} \mathrm{O}_{5} / \mathrm{Sr}_{6} \mathrm{Bi}_{2} \mathrm{O}_{11}$ heterostructure: the introduction of a relatively small (about $10 \%$ ) amount of $\mathrm{Sr}_{2} \mathrm{Bi}_{2} \mathrm{O}_{5}$ significantly reduces the absorption of the heterostructure compared to the absorption of pure $\mathrm{Sr}_{6} \mathrm{Bi}_{2} \mathrm{O}_{11}$. For the $\mathrm{Sr}_{3} \mathrm{Bi}_{2} \mathrm{O}_{6} / \mathrm{Sr}_{6} \mathrm{Bi}_{2} \mathrm{O}_{11}$ heterostructure, on the contrary, an increase in the absorption of the heterostructure is observed compared with the absorption of pure $\mathrm{Sr}_{6} \mathrm{Bi}_{2} \mathrm{O}_{11}$ with the introduction of a relatively small (about $10 \%$ ) amount of $\mathrm{Sr}_{3} \mathrm{Bi}_{2} \mathrm{O}_{6}$.

\section{Photocatalytic Activity Test}

The photocatalytic activity of all synthesized heterostructures was investigated by the decomposition of phenol in aqueous solution in a batch-type reactor with lateral quartz window. The photoreactor was subjected to simulated solar light irradiation under ambient conditions. Prior to irradiation, aqueous suspensions of the heterostructures $(1.0 \mathrm{~g} / \mathrm{L} ; \mathrm{pH}=7.0 ; 300 \mathrm{~mL})$ were pretreated in an ultrasonic processor for $10 \mathrm{~min}$, followed by addition of phenol (100 ppm; purity $99.5 \%$, Aldrich) to the suspensions and then magnetically stirred for $1 \mathrm{~h}$ in the dark to achieve adsorption/desorption equilibria. The initial concentration of phenol was such that the photoreaction kinetics was independent of concentration. The light source was a $150 \mathrm{~W}$ Xe lamp (OSRAM); an optical cutoff filter ascertained the removal of UV wavelengths below $300 \mathrm{~nm}$ (light irradiance $\left.7 \mathrm{~mW} / \mathrm{cm}^{2}\right)$.

Aliquot samples were collected at given intervals and filtered through a $0.2 \mu \mathrm{m}$ Minisart filter to remove solid particles prior to HPLC analysis to determine the phenol concentration on a 1260 Infinity liquid chromatograph equipped with a UV-Vis detector and a C18 column (Agilent 
Technologies). The mobile phase was a 50/50 v/v mixture of methanol/water; detection wavelength was $210 \mathrm{~nm}$ at a bandwidth of $4 \mathrm{~nm}$. The photocatalytic activity of the samples was estimated by the rate of photodegradation of phenol using the kinetic expressions (eqns (1) and (2)):

$$
\begin{aligned}
& C(t)=C_{0} \cdot \exp (-k t) \\
& d C / d C_{(t \rightarrow 0)}=-k C_{0},
\end{aligned}
$$

where $k$ is a quasi-first-order rate constant.

In Fig. 4 shows the photocatalytic activity of strontium bismuthate-based heterostructures. It can be seen that the creation of heterostructures based on various strontium bismuthates greatly changes not only their optical properties but also affects the photocatalytic activity.

The $\mathrm{Sr}_{2} \mathrm{Bi}_{2} \mathrm{O}_{5} / \mathrm{Sr}_{6} \mathrm{Bi}_{2} \mathrm{O}_{11}$ heterostructure does not possess photocatalytic activity, despite the fact that its base is made up of the highly active strontium bismuthate $\mathrm{Sr}_{6} \mathrm{Bi}_{2} \mathrm{O}_{11}$. The $\mathrm{Sr}_{3} \mathrm{Bi}_{2} \mathrm{O}_{6} / \mathrm{Sr}_{6} \mathrm{Bi}_{2} \mathrm{O}_{11}$ heterostructure has a photocatalytic activity higher than that of $\mathrm{Sr}_{3} \mathrm{Bi}_{2} \mathrm{O}_{6}$, but significantly lower than that of $\mathrm{Sr}_{6} \mathrm{Bi}_{2} \mathrm{O}_{11}$. Of greatest interest is the photocatalytic activity of the $\mathrm{Sr}_{2} \mathrm{Bi}_{2} \mathrm{O}_{5} / \mathrm{Sr}_{3} \mathrm{Bi}_{2} \mathrm{O}_{6}$ heterostructure. Its basis $(95 \%)$ is strontium bismuthate $\mathrm{Sr}_{3} \mathrm{Bi}_{2} \mathrm{O}_{6}$ possessing a certain photocatalytic activity. Moreover, the addition of only 5\% of photocatalytically inactive $\mathrm{Sr}_{2} \mathrm{Bi}_{2} \mathrm{O}_{5}$ reliably and quite significantly increases the photocatalytic activity of the resulting heterostructure.

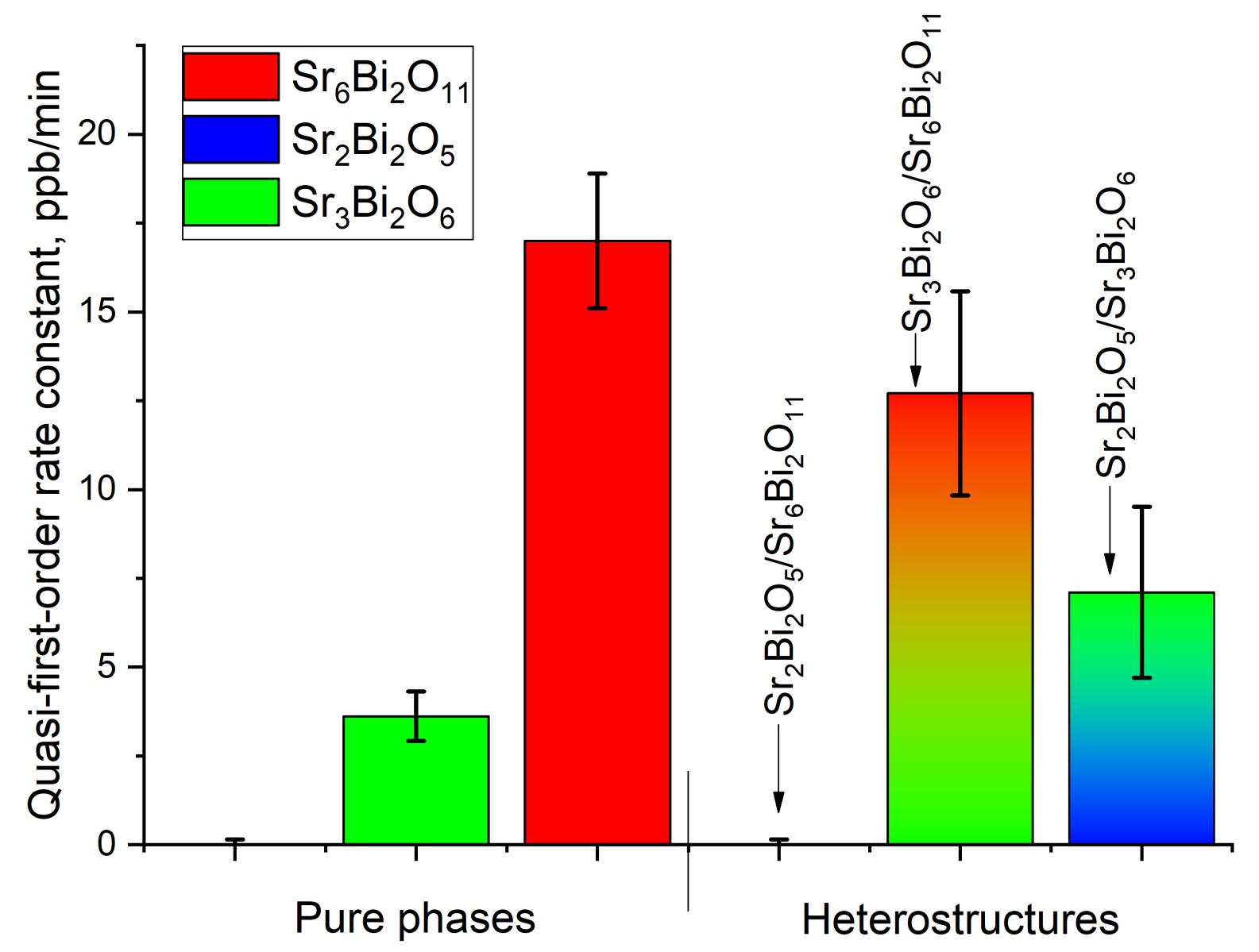

Fig. 4. Photocatalytic activity of strontium bismuthate-based heterostructures. For comparison, the photocatalytic activities of the pure phases of strontium bismuthate (taken from [7]).

Apparently, the observed effect of an increase in photocatalytic activity in heterostructures is associated with the stabilization of surface defects, which are centers of photocatalytic reactions. However, a more detailed study of the mechanism of stabilization of surface defects and their effect on photocatalytic activity is to be established in the course of further research. 


\section{Conclusion}

Studies have shown the promise of further studies of the photocatalytic activity of heterostructures consisting of various strontium bismuthates. In particular, it has been shown that the photocatalytic activity of individual strontium bismuthates can be significantly increased by introducing a small amount (of the order of a few percent's) of another, even photocatalytically inactive, strontium bismuthate. In Fig. 1 shows that the photocatalytic properties of seven different strontium bismuthates have now been investigated. This makes it extremely promising to create new heterostructures based on two different strontium bismuthates and to study the characteristics of their photocatalytic activity.

\section{Acknowledgement}

The research was carried out at the expense of a grant from the Russian Science Foundation (project No. 17-73-00007).

\section{References}

[1] Yang Yingchun, Wang Xinzhi, Qu Jing. Preparation and photocatalytic degradation of malachite green by photocatalyst $\mathrm{SrBi} 4 \mathrm{O} 7$ under visible light irradiation. Applied Mechanics and Materials Vols. 522-524 (2014) 411-415.

[2] Wenjun Zhou, Xinyi Yu. Use of Sr2Bi2O5 as photocatalyst for the degradation of acid red G. Desalination and Water Treatment Vol. 30:1-3 (2011) 295-299.

[3] Zhichao Shan, Yujuan Xia, Yuxiang Yang, Hanming Ding, Fuqiang Huang. Preparation and photocatalytic activity of novel efficient photocatalyst Sr2Bi2O5. Materials Letters Vol. 63 (2009) $75-77$.

[4] Y. Obukuro, S. Matsushima, K. Obata, T. Suzuki, M. Arai, E. Asato, Y. Okuyama, N. Matsunaga, G. Sakai, Effects of La doping on structural, optical, electronic properties of Sr2Bi2O5 photocatalyst, Journal of Alloys and Compounds (2015), doi: 10.1016/j.jallcom.2015.10.199.

[5] Xuexiang $\mathrm{Hu}$, Chun $\mathrm{Hu}$, Jiuhui Qu. Photocatalytic decomposition of acetaldehyde and Escherichia coli using $\mathrm{NiO} / \mathrm{SrBi} 2 \mathrm{O} 4$ under visible light irradiation. Applied Catalysis $\mathrm{B}$ : Environmental Vol. 69 (2006) 17-23.

[6] Chun $\mathrm{Hu}$, Xuexiang $\mathrm{Hu}$, Jian Guo, Jiuhui Qu. Efficient Destruction of Pathogenic Bacteria with $\mathrm{NiO} / \mathrm{SrBi} 2 \mathrm{O} 4$ under Visible Light Irradiation. Environ. Sci. Technol. 2006, 40, 5508-5513.

[7] Shtarev D.S., Shtareva A.V., Ryabchuk V.K., Rudakova A.V., Murzin P.D., Molokeev M.S., Koroleva A.V., Blokh A.I., and Nick Serpone. Solid-State Synthesis, Characterization, UV-Induced Coloration and Photocatalytic Activity - The Sr6Bi2O11, Sr3Bi2O6 and Sr2Bi2O5 Bismuthates. Catalysis Today. DOI: 10.1016/j.cattod.2018.09.035.

[8] B, Hallstedt, L, J. Gauckler, Revision of the thermodynamic descriptions of the $\mathrm{Cu}-\mathrm{O}, \mathrm{Ag}-\mathrm{O}$, $\mathrm{Ag}-\mathrm{Cu}-\mathrm{O}, \mathrm{Bi}-\mathrm{Sr}-\mathrm{O}, \mathrm{Bi}-\mathrm{Ca}-\mathrm{O}, \mathrm{Bi}-\mathrm{Cu}-\mathrm{O}, \mathrm{Sr}-\mathrm{Cu}-\mathrm{O}, \mathrm{Ca}-\mathrm{Cu}-\mathrm{O}$ and $\mathrm{Sr}-\mathrm{Ca}-\mathrm{Cu}-\mathrm{O}$ systems. Computer Coupling of Phase Diagrams and Thermochem., 27 (2003) 177-191.

[9] D.S. Shtarev, N.F. Karpovich, A.V. Shtareva, A.I. Blokh, E.O. Nashchochin. Solid-phase synthesis and photocatalytic activity of strontium bismuthates $\mathrm{Sr}_{\mathrm{x}} \mathrm{Bi}_{\mathrm{y}} \mathrm{O}_{\mathrm{z}}(\mathrm{x}>\mathrm{y})$. Bulletin of FEB RAS. 198 (2018) 237-247 (in Russian). 